quality studies with good quantitative long-term exposure data. Although minor or acute inflammatory effects might occur before the detection of silicosis, low-grade silicosis and lung cancer are the only chronic effects which could so far be assessed with reasonable confidence in epidemiological studies.

The available data would support threshold limit values for occupational exposure to crystalline silica in the range of 50 to $100 \mu \mathrm{g} / \mathrm{m}^{3}$ which are already in place in several countries.

\section{MEDICHEM SYMPOSIUM: OCCUPATIONAL AND ENVIRONMENTAL IMPACTS ON THE HUMAN GENOME}

Avi Wiener*. Faculty of Civil and Environmental Engineering, Technion - Israel Institute of Technology (ITT), Haifa, Israel

\subsection{6/oemed-2018-ICOHabstracts.1031}

Aim of special session This session explores links between occupational and environmental chemical exposures and genelevel mutations and gene regulation, contributing to disease causation

Dr. Dov Hershkovitz ${ }^{1}$, Dr. Geula Klorin ${ }^{2}$, Dr. Avi Wiener ${ }^{3}$

${ }^{1}$ Tel-Aviv Sourasky Medical Centre and Faculty of Medicine, Tel-Aviv, Israel

${ }^{2}$ Tel-Aviv Sourasky Medical Centre and Faculty of Medicine, Haifa, Israel

${ }^{3}$ Faculty of Civil and Environmental Engineering, Technion - Israel Institute of Technology (ITT), Haifa, Israel

\section{3a THE HUMAN GENOME AND MUTATION SIGNATURES OF ENVIRONMENTAL FACTORS}

D Hershkovitz. Tel-Aviv Sourasky Medical Centre and Faculty of Medicine, Tel-Aviv, Israel

10.1136/oemed-2018-ICOHabstracts.1032

The human genome is comprised of sequences of three billion DNA nucleic acids. Analysis of DNA sequencing has improved our understanding of many molecular processes relevant for normal physiology and disease. Genetic alterations are the basis of cancer development and can be divided into germline and somatic mutations. While germline mutations are hereditary, somatic mutations are acquired throughout life as a consequence of DNA replication errors, or from some environmental insult such as smoking, occupational or environmental carcinogen exposures, and ultra-violet irradiation. Analysis of the genomic sequence of tumours can identify mutation signatures specific for some environmental factors and direct guidelines for recommended exposure limits and cancer prevention.

\section{3b INTEGRATIVE GENOMIC ANALYSIS OF MALIGNANT MESOTHELIOMA CELL LINES DERIVED FROM PATIENTS WITH ASBESTOS EXPOSURE}

${ }^{1,2} \mathrm{G}$ Klorin*, ${ }^{2} \mathrm{~A}$ Roschke. ' Rambam Health Care Campus, Haifa, Israel; ${ }^{2}$ Genetics Branch, $C C R, N C l, N I H$, Bethesda, MD, USA

10.1136/oemed-2018-ICOHabstracts.1033
Introduction Malignant mesothelioma (MMt) is a rare cancer that occurs in the thin layer of tissue that covers the majority of internal organs (i.e., the mesothelium). Mesothelioma most often affects the tissue that surrounds the lungs (pleura). About $90 \%$ of cases are related to exposure to asbestos fibres. The period of latency from the moment of exposure to the development of the disease is very prolonged and typically 40-50 years. Genetic analysis of MMt cells revealed changes possibly responsible for the development and progression of MMt.

Methods High-resolution oligonucleotide array comparative genomic hybridization (aCGH) and spectral karyotyping (SKY) were applied to a panel of MMt cell lines.

Result Numerous recurrent karyotypic abnormalities have been delineated, and heterogeneity of chromosomal rearrangements were detected in MMt cell lines. A whole genome search for homozygous deletions (HDs) produced the largest set of recurrent and non-recurrent $\mathrm{HDs}$ for $\mathrm{MMt}$; some genes located there could be new tumour suppressors for MMt. The smallest recurrent $\mathrm{HD}$ regions affected genes CDKN2A/CDKN2B, LINGO2, RBFOX1/A2BP1，NF2，RPL29，DUSP7，CCSER1/ FAM190A, LATS2. Integrative analysis revealed that acquisition of numerical and/or structural karyotypic instability allows MMt cells to attain a complete loss of tumour suppressor genes located in 9 p21.3, which is the most frequently homozygously deleted region.

Discussion Chromosomal heterogeneity detected in MMt cell lines points to the presence of structural and numerical chromosomal instability in these cells. It is reasonable to suggest that only with the acquisition of structural or numerical chromosomal instability could MMt cells attain a complete loss of tumour suppressor genes. Aneuploidy of MMt karyotypes as well as the presence of structural and numerical chromosomal heterogeneity makes MMt tumours possible candidates for treatment by anti-cancer drugs that target cells with aneuploid, karyotypically unstable phenotypes.

\section{C VARIOUS IMPACTS OF INDUSTRIAL POLLUTANTS ON GENE EXPRESSION}

A Wiener. Faculty of Civil and Environmental Engineering, Technion - Israel Institute of Technology (ITT), Haifa, Israel

\subsection{6/oemed-2018-ICOHabstracts.1034}

Environmental Toxicology deals with the deleterious effects of anthropogenic pollutants and ionising radiation on plants, animals, and humans. Specific industrial and agricultural chemicals might cause mutagenic, teratogenic and, carcinogenic expressions of genes. Obviously these outcomes indicate that genetic defense mechanisms failed to overcome or to repair gene damage. Gene expression is regulated by structural and chemical modifications of DNA. Anthropogenic pollutants might interfere with the gene regulatory network. The existence of homologue genes shared by some animals and humans enables us to investigate the pathological effects of pollutants on animal models and to relate these relevant mechanisms to humans. This presentation will demonstrate various deleterious mechanisms of harmful chemicals that cause obesogenic, endocrine disruptive, and carcinogenic effects. 